\title{
Possíveis relações entre corpo, saúde e o envelhecimento do professor de Educação Física
}

\author{
Alan Camargo Silva* \\ Sílvia Maria Agatti Lüdorf*
}

\begin{abstract}
Resumo: Nota-se na literatura a escassez de estudos voltados à compreensão sobre como o envelhecer pode afetar o professor de Educação Física. O objetivo desta pesquisa foi investigar se (e quais são os significados atribuídos) a saúde emerge nas relações entre o envelhecimento do professor de Educação Física e seu próprio corpo. As preocupações do professor, imbricadas à saúde e ao envelhecimento, se referem à funcionalidade do corpo, estabilidade financeira, não ter doenças e se tornar senil. Os cuidados que o professor adota para um envelhecer saudável são as práticas corporais e a adoção de uma alimentação equilibrada.
\end{abstract}

Palavras-chave: Corpo. Envelhecimento. Docentes. Educação Física.

\section{Considerações INTRODUTÓRIAS}

Os estudos voltados para o envelhecimento, sobretudo pelo prisma humano e social, coincidem com a descoberta e maior preocupação com a velhice por parte da sociedade (BARROS, 2007). A partir dos anos 70 é que a temática do envelhecimento passa a receber um tratamento acadêmico, transformando-se em temas de pesquisa e de estudos nas universidades (DEBERT, 2004).

\footnotetext{
"Escola de Educação Física e Desportos da Universidade Federal do Rio de Janeiro. Núcleo de Estudos Sociocorporais e Pedagógicos em Educação Física e Esportes. Rio de Janeiro, RJ Brasil..E-mail: alan10@zipmail.com.br

"Escola de Educação Física e Desportos da Universidade Federal do Rio de Janeiro. Núcleo de Estudos Sociocorporais e Pedagógicos em Educação Física e Esportes. Rio de Janeiro, RJ. Brasil. E-mail: sagatti@ufrj.br
} 
Nesse contexto, a presente pesquisa trata, mais especificamente, sobre o envelhecimento do professor de Educação Física que poderia apresentar indícios de certas particularidades e diversidades associadas ao seu corpo e à sua saúde. Petry e Garces (2009) identificaram que o professor de Educação Física, ao refletir sobre o seu próprio envelhecimento, possui preocupações e cuidados especiais com/para a saúde a fim de retardarem principalmente os efeitos físico-biológicos do corpo.

Ao longo dos anos o foco dos estudos sobre o professor voltavase principalmente para a competência técnica do docente, deixando em segundo plano a análise da dimensão subjetiva do professor (NÓVOA, 2007). Há indícios de que o professor possui uma forma de interagir com a vida pessoal muitas vezes atrelada à própria profissão (TARDIF; RAYMOND, 2000; STANO, 2001).

O professor de Educação Física (in)diretamente está/é envolvido pelos ideais corporais contemporâneos (LÜDORF, 2010). Nesse sentido, com base na ideia de Le Breton (2003) de que o corpo é uma construção sociocultural, argumenta-se que o professor desenvolve possivelmente hábitos e costumes específicos da profissão e da cultura na qual está imerso, ao longo da carreira. Em determinado período histórico, cada grupo social concebe diferentemente o corpo e seus cuidados (prioridades e limites) do que seria (a)normal em relação à saúde devido à seus princípios, experiências e crenças (VICTORA et al., 2000).

Há a necessidade de valorizar as variadas experiências e discursos específicos de cada grupo social em relação ao corpo e à saúde (MINAYO, 2006). A premissa é que os professores de Educação Física, ao envelhecerem na profissão, constituem um grupo (heterogêneo), que possui tendências de cuidar do próprio corpo. Esta aparente particularidade de vivenciar a profissão pode ser justificada na medida em que a docência propicia o que Stano (2001) nomeia de habitus socioprofissional ou o que Tardif e Raymond (2000) chamam de identidade do trabalhador. 
A partir da revisão de literatura realizada em bases de dados nacionais e internacionais ${ }^{1}$, bem como em demais periódicos da área de Educação Física que não estão indexados nas bases referidas, foi possível detectar que não há estudos sobre o processo de envelhecimento na profissão docente e nem especificamente sobre o professor de Educação Física, com exceção do estudo de Petry e Garces (2009). O que pôde ser visto é que os estudos sobre o professor de Educação Física se dirigem principalmente à carreira, às trajetórias profissionais, aos aspectos relacionados às condições de trabalho e à construção dos saberes docentes. No entanto, no que se refere às concepções do professor de Educação Física sobre o seu corpo e a sua saúde com o passar dos anos ainda são inexistentes no âmbito acadêmico. Debert (2004) afirma que é primordial conhecer e analisar as redes de poder, descrever costumes, valores e práticas sociais que não estão registrados em linguagem escrita.

Desse modo, o objetivo desta pesquisa, é investigar se (e quais são os significados atribuídos) a saúde emerge nas relações entre o envelhecimento do professor de Educação Física e seu próprio corpo.

\section{Procedimentos metodológicos}

Nesta pesquisa, de natureza qualitativa, foram selecionados 32 professores(as) de Educação Física atuantes em escolas e/ou em academias de ginástica (identificados por P1 a P32), na faixa etária 40 a 60 anos, estando na prática profissional entre 15 a 25 anos, fase que geralmente ainda não há um total desinvestimento na profissão docente e nem um maior cuidado de si (HUBERMAN, 2007). No caso, 19 homens, sendo 13 pós-graduados, 14 com filhos e apenas 1 com netos; e 13 mulheres, sendo 11 pós-graduadas, 12 com filhos e apenas 3 com netos.

Utilizou-se a entrevista semiestruturada como instrumento de coleta de dados a fim de conhecer a opinião do professor no que

\footnotetext{
${ }^{1} \mathrm{~A}$ busca de trabalhos foi empreendida principalmente nas seguintes bases de dados: SciELO, LILACS, IBECS, MEDLINE, Biblioteca Cochrane, ISI, ERIC e SCOPUS.
} 
concernem as suas compreensões da relação entre corpo, saúde e o próprio envelhecimento. A quantidade de entrevistas foi norteada pelo ponto de "saturação", ou seja, a pesquisa foi interrompida à medida que o nível da recorrência dos dados foi se elevando (GASKELL, 2003).

Inicialmente a análise de dados foi realizada através da "leitura flutuante" das entrevistas transcritas, obtendo impressões preliminares a fim de selecionar as primeiras tendências de achados. Após esse processo de leituras e releituras do corpus, houve a análise de conteúdo que propiciou a elaboração de categorias a partir dos princípios de repetição e de relevância, como Turato (2003) propõe.

Foi fornecido o Termo de Consentimento Livre e Esclarecido a todos os professores participantes, respeitando os preceitos éticos para pesquisas realizadas com seres humanos. A presente pesquisa foi aprovada pelo Comitê de Ética em Pesquisa do Instituto de Estudos em Saúde Coletiva da Universidade Federal do Rio de Janeiro (processo 52/2008 e parecer 04/2009).

\section{APRESENTAÇÃo e discussão dos RESULtAdos}

A discussão a seguir privilegiará como os significados atribuídos ao corpo e à saúde pelo professor emergiram no bojo das suas preocupações e de seus cuidados com o processo de envelhecimento.

\subsection{Preocupações do PROfessor de Educação Física ao enVelhe- CER}

O professor, ao se remeter às possíveis preocupações em relação ao seu envelhecimento, restringe-se principalmente à categoria que foi denominada de funcionalidade do corpo, geralmente associada à perspectiva da saúde:

A minha parte de saúde, hoje eu me preocupo muito mais com a minha saúde, com o meu corpo, do que anos atrás, né? [...] Essa condição de viver o dia a dia, as dificuldades vão surgindo, né? Você pensa, 
mas teu corpo não obedece, isso começa a incomodar um pouco, né? [...] à medida que vai passando o tempo, você sente mais dificuldade no dia a dia, de fazer suas atividades normais [...] (P5 - Professor de Educação Física escolar, 47 anos)

O que eu mais me preocupo no meu corpo, mais em termo de saúde, então, no caso é saúde [...] o principal acho que é o fator da saúde "pra" eu me sentir, até "pro" processo de envelhecimento, ter um processo de envelhecimento mais prazeroso vamos dizer assim, não ter tanto, não sentir tanto os efeitos da velhice como as pessoas sentem por falta de prática de exercício e tudo mais, mas eu acho que o principal motivo é a saúde mesmo. (P6 - Professor de Musculação e personal trainer, 42 anos)

Esses achados podem indicar que o professor de Educação Física ao envelhecer possui uma maneira típica de lidar com o próprio corpo, quando ressaltam constantemente a necessidade de se manter em atividade. No atual estágio de vida, provavelmente, pelos professores estarem vivenciando (ou próximos de vivenciar) o suposto declínio dos aspectos físico-biológicos vinculados ao processo de envelhecimento, a saúde estaria relacionada ao corpo capacitado para realizar atividades consideradas simples do cotidiano, muitas vezes comprometidas com o passar dos anos.

O professor que ao longo do tempo está acostumado com a prática corporal, com a dinâmica dos movimentos e, talvez, principalmente, a estimular os alunos a todo o momento à exercitação do corpo, teme as possíveis limitações físico-biológicas, relacionadas ao processo de envelhecimento. Petry e Garces (2009) detectaram que as preocupações dos professores de Educação Física se dirigem justamente aos aspectos negativos do envelhecer, sobretudo ao declínio biológico do organismo e da saúde fazendo com que receiem a perda da funcionalidade do corpo.

A funcionalidade do corpo relativa à saúde também estaria ligada à manutenção dos diferentes papéis sociais e culturais assumidos ao longo da vida pelo professor: 
Cara, saúde é você conseguir viver, viver sua vida, principalmente dentro do trabalho e fora do trabalho, de forma que você, é não ficar na cama, meu irmão, é isso, porque eu acho que a partir do momento que você consegue trabalhar, você consegue cuidar dos seus filhos, consegue viver a sua vida em casa e no trabalho, então, saúde para mim é isso. (P11 Professor de Musculação, 45 anos)

(Saúde é) ter, ter disposição "pra" fazer as coisas, "pra" trabalhar, "pra" passear, sei lá, "pra" correr, "pra" caminhar [...] Assim, saúde é você "tá" bem, né? "Tá" assim, sei lá, com todas as suas, os seus afazeres sendo cumpridos, porque você tem condição de fazer e não tem nada que te impeça. (P20 - Professora de Educação Física escolar, 55 anos)

Gardner (2006) afirma que a capacidade funcional não pode ser vista apenas como uma habilidade com um fim em si mesma, mas também como um meio ligado à possibilidade de se envolver e participar da vida diária. Um "corpo funcional" significaria independência de natureza física e de relacionamento na vida pessoal tanto com amigos quanto com familiares, bem como trabalhar se isentando de qualquer incômodo. Estar livre de obstáculos físicos de maneira autônoma e com vitalidade é um requisito importante, interpretado pelos professores como positivos para a saúde.

Outra preocupação mais ressaltada pelos professores quando se remetem ao próprio envelhecer é a insegurança/instabilidade financeira:

Eu agora me preocupo mais, em relação com aposentadoria, como é que vai ficar meu dinheiro [...] então, eu não quero gastar com médico não. Então, eu penso assim, eu não quero parar de trabalhar, mas eu quero trabalhar só três vezes na semana. (P2 - Professora de Educação Física escolar, 57 anos)

Então, vou falar uma coisa que eu não fico prosa, não fico orgulhosa não, como o professor de Educação Física é muito duro ainda de grana, tem 
que ralar muito para o dinheiro entrar num nível médio para bom, longe do ótimo. Eu não posso pagar para ter aula, para receber massagem e um plano de saúde, agora o plano de saúde vai tratar de mim quando eu estiver doente [...] (P23 - Professora de terapia corporal, 53 anos)

Nesses casos, as preocupações dos professores de Educação Física com o envelhecer não se referem diretamente com tanta intensidade ao corpo propriamente dito, o que talvez poderia ser esperado, uma vez que a profissão lida com/para o corpo. Há para determinados professores certa expectativa em melhorar a condição financeira para si, para a sua família e para a sua própria saúde.

A escolha do professor é trabalhar, muitas vezes, além dos seus próprios limites físicos, transparecendo que a própria profissão não contribui para a saúde dos profissionais. Há evidências de que o professor de Educação Física possui a necessidade de trabalhar em vários locais ou com a carga horária extenuante para manter as condições financeiras (SILVA; NUNEZ, 2009). A saúde do professor é de certa maneira afetada na medida em que a preocupação com uma estabilidade financeira se torna cada vez mais urgente com o envelhecimento.

Outra preocupação que ficou caracterizada nos discursos dos professores seria com as possíveis doenças ao envelhecer:

[...] tenho preocupações, cardiopatias [...] então, eu faço o meu melhor pra não cair na genética imperfeita e as preocupações são essas, de manutenção de saúde. (P3 - Professor de Musculação e personal trainer, 54 anos)

[...] a minha preocupação é não ficar doente, né? [...] então, eu me cuido, procuro me cuidar, não tanto como eu queria, mas eu me cuido "pra" justamente não ter doenças, que eu poderia ter evitado ao longo do tempo, né? [...] Eu sempre, eu sempre me cuidei "pra" que eu não viesse a sofrer no futuro desses males que a gente poderia ter evitado, então, eu "tô" bem tranquilo, né? [...] A 
minha preocupação mesmo é cuidar da saúde mesmo, eu tenho essa preocupação mesmo. (P8 Professor de Educação Física escolar, 45 anos)

Conforme Ortega (2003), muitas vezes o envelhecimento é definido em termos de declínio à idade adulta cujos sinais da idade tornam-se marcas de um estado patológico. Parece que há a ideia de que saúde é sinônimo de não ter doenças e que está relacionada diretamente ao corpo físico e velho. Os professores de Educação Física aparentemente não compreendem que um envelhecimento saudável pode ocorrer na presença de doenças ou de outras privações, como já detectado e discutido em outros estudos (BLESSMANN, 2004; GARDNER, 2006). A exacerbada preocupação com doenças, como sinônimo de "ausência de saúde" são notórios, na medida em que para um grupo de professores, se tornar mais velho significa estar cada vez mais próximo da "falta de saúde".

Se por um lado, os professores ao envelhecerem se preocupam de maneira exacerbada com o corpo físico (funcional e sem doenças) como visto nas categorias supracitadas, por outro, a dimensão mental, outra categoria que emergiu dos discursos, é pouco citada:

De você, se preocupar com a questão intelectual, né? Porque, eu, eu acho que isso é um maior desafio quando a gente "tá" envelhecendo, é a gente estar motivado a buscar coisas novas, né? Esse campo novo, eu acho que é o maior desafio [...] então o conceito de saúde que eu vejo é isso, é você buscar novas possibilidades no campo do intelecto. (P8 Professor de Educação Física escolar, 45 anos)

A única preocupação que eu tenho é manter-me lúcido para compreender de forma agradável a vida, essa é a minha preocupação [...] Então eu vou buscando as coisas, vou tentando cada vez mais compreender o mundo a minha volta, e para isso eu preciso estar atento as coisas, e talvez isso me dê uma sanidade e uma lucidez boa, que me favorece. Então a preocupação é essa mesma, de ter uma saúde global, uma saúde não só em questão da estética, mas uma saúde do todo, do interior. (P27 Professor de Educação Física escolar, 53 anos)

Movimento, Porto Alegre, v. 18, n. 02, p. 187-204, abr/jun de 2012. 
Debert (2004) e Barros (2007) frisam que, pelo fato de se distanciar da relação/papel social e comprometer os projetos de vida, grande parte das pessoas ao envelhecerem se preocupa com o aspecto intelectual, cognitivo e com características atreladas à sanidade mental. Tendo em vista o envelhecimento, parece que o professor de Educação Física se depara com um dualismo ao valorizar notoriamente mais o corpo do que às questões relacionadas à mente. Pode-se afirmar, que para alguns professores, estar "antenado" com o mundo significa envelhecer com saúde.

Além disso, ainda no bojo das preocupações, grande parte dos professores sente o envelhecer de maneira diferenciada quando se remetem ao corpo e à mente:

[...] (envelhecer) depende muito da cabeça da pessoa, acho que muitos envelhecem na cabeça, e de certa forma, o corpo acompanha, se elas se sentem velhas, elas tão, elas ficam muito mais velhas antes do tempo. (P6 - Professor de Musculação e personal trainer, 42 anos)

[...] agora cabeça (mente) "pra" mim, eu nunca vou ser velho assim de cabeça entendeu? [...] então, eu acho que envelhecer é a mais a parte física mesmo (P7 - Professor de aulas coletivas, 44 anos)

[...] a parte físico-orgânica (envelhece) primeiro, acho que degenera mais rápido. (P12 - Professor de aulas coletivas, 47 anos)

A cabeça sempre funcionando, ela envelhece mais rápido do que o corpo, então, eu, eu tomo conta disso daí, eu vou me administrando nisso aí (P13 Professor de Educação Física escolar, 60 anos)

Eu percebo que eu "tô" velha por algumas coisas, né? Mas a minha cabeça não "tá", de repente, se eu parar de usar o meu corpo em alguma atividade, eu acho que o meu corpo vai envelhecer antes da cabeça, entendeu? Por enquanto eu acho que "tá" bem equilibrado, né? (P20 - Professora de Educação Física escolar, 55 anos) 
[...] a cabeça também, a cabeça envelhece é, não falo de doenças tipo Alzheimer, essas coisas todas que você esquece é, se você se ocupa, a tua cabeça não envelhece, teu corpo pode até envelhecer, você tem recursos, né? Recursos "pra" melhorar o teu corpo, agora a falta de ocupação, acho que envelhece muito mais a cabeça e aí acho que juntando isso tudo aí, é terrível. (P26 - Professora de aulas coletivas, 40 anos)

Então eu olho, me olho no espelho, caramba! A cabeça continua com 18 (anos), a "carcaça" (aparência do corpo) já está diferente, claro [...] Eu acho que o corpo envelhece, mas a mente envelhece se você permitir. (P29 - Professora de Educação Física escolar, 53 anos)

$\mathrm{O}$ aspecto físico geralmente seria o que mais compromete durante o processo de envelhecimento, pois o corpo estaria se apresentando como velho. A ideia de Le Breton (2003) de que o corpo pode ser considerado um estorvo ou uma ameaça ao sujeito, é vista nos depoimentos, quando a centralidade do corpo é perceptível para os professores ao pensarem no próprio envelhecer. Segundo Blessmann (2004) e Vincent (2008), historicamente há uma compreensão de envelhecimento a partir de uma divisão cartesiana entre corpo e mente, que inviabiliza a noção de totalidade do sujeito.

\subsection{Cuidados adotados pelo professor de Educação Física aO ENVELHECER}

Surgem algumas evidências de que o professor de Educação Física, ao visualizar o próprio envelhecimento, adota cuidados voltados a comportamentos considerados saudáveis, caracterizando uma cobrança de si com intuito de retardar ou monitorar o passar dos anos basicamente pela prática corporal e alimentação:

Sempre faço atividade (física) direto. [...] Me sinto impressionado como é que as pessoas não gostam, isso aí me deixa até meio grilado, entendeu? [...] como (outra pessoa) consegue viver sem gostar disso (atividade física), de se conhecer melhor, de se testar, 
né cara? [...] Eu gosto, eu gosto de pegar onda, gosto de jogar um Squash, mas fora de atividade? Tipo assim [...] também procuro comer dentro de uma dieta legal, balanceada, sem muito exagero, mas só também. Não passo "creminho" (creme). (P4 Professor de Educação Física escolar e personal trainer, 50 anos)

Acho que a alimentação, né? Que está diretamente ligada também, a parte de saúde e o fundamental a tua condição saudável "pra" você ter uma boa qualidade de vida, isso aí qualquer ser humano tem que ter, porque os anos chegam mesmo, não tem jeito e se você tiver mal [...] dependendo do momento que você estiver, "pra" você conseguir recuperar essa forma, é muito difícil, é muito difícil mesmo. Então, quanto mais você deixar passar, sem fazer essas atividades (físicas), mas difícil vai ser você recuperar esse tempo perdido aí e a tendência são as doenças começarem a aparecer, né? E você não reagir, então eu acho que o ser humano tem que fazer atividade física até o final, não tem jeito, isso aí é uma obrigatoriedade de todos, de todo o ser, não tem como. (P5 - Professor de Educação Física escolar, 47 anos)

Transparecem nas falas dos professores cuidados com/para a longevidade que são amplamente valorizados e propagados no/pelo senso comum. Ao vislumbrar o envelhecimento, o corpo, de acordo com as palavras de Le Breton (2003), se tornaria o próprio "parceiro" do professor de Educação Física, uma vez que se caracteriza por um local de reconquista de si e por um espaço ainda a ser aprimorado.

As práticas corporais geralmente são consideradas ferramentas-chave na luta contra o envelhecimento (KATZ, 2000; TULLE, 2008) e à favor de uma longevidade saudável (LAZ, 2003). A maioria dos professores parece não se aperceber que apenas os comportamentos modificados são insuficientes para a melhora da saúde, uma vez que há uma complexidade sociocultural e econômica que rege as escolhas de adoção de estilos de vida (BAGRICHEVSKY; PALMA, 2004). Petry e Garces (2009) 
também verificaram a tendência dos professores valorizarem a alimentação e a prática corporal visando um envelhecimento bemsucedido - leia-se saudável.

Raros foram os relatos referentes à adoção de cuidados "saudáveis" com/para envelhecimento para além da prática corporal e alimentação equilibrada:

É, estudo, estudo, (para) manter a mente ativa, leitura, leitura, música, eu vivo muito, sem música eu não vivo, livro e leitura, $\mathrm{CD}, \mathrm{CD}$, música, gosto dos meus dois violões. (P3 - Professor de Musculação e personal trainer, 54 anos)

$\mathrm{Na}$ minha carreira como professor, eu sempre tive tempo [...] tempo para estudar, para dormir [...] eu tinha minhas rotinas sempre muito regulares, sempre trabalhei perto da minha casa, sempre organizei minha vida de modo [...] eu sou muito organizado, eu agendo toda minha vida, eu programo ela direitinho, eu programo minhas rotinas [...] eu tenho as horas de dedicar ao meu lazer, eu tenho as horas de me dedicar a minha família, eu tenho minhas horas para me dedicar para mim. (P17 - Personal trainer, 45 anos)

Se a gente não achar e não priorizar esse tempo para gente, que exclui movimento, ler, orar, não adianta que o resto não vai achar o tempo, não vai sobrar. (P23 - Professora de terapia corporal, 53 anos)

Em menor grau, a tônica dos discursos se dirige para outros cuidados como a prática do lazer, o tempo para se dedicar às faculdades mentais, o entretenimento, o descanso e minimamente para as relações sociais. Um profissional considerado da saúde, que estuda/trabalha o corpo e está formado há um tempo, apesar do seu repertório técnico-científico e acúmulo de vivências da prática, ainda se remete a um conjunto reduzido de fatores que compõem os cuidados com o próprio corpo. Nesse caso, é preciso levar em consideração que o corpo é socialmente construído (LE BRETON, 
2003), ou seja, baseando-se em Lupton (2000), certas práticas para si devem ser consideradas maneiras de modo de vida culturalmente elaboradas.

Para um grupo de professores, os cuidados com o envelhecer sempre foram referências no modo de viver, criando certo automonitoramento ao longo dos anos:

$\mathrm{Eu}$ sinto que elas (as pessoas em geral) gostariam de ter esse costume que eu fui adquirindo ao longo da vida e que elas não conseguem ter hoje em dia até porque não foram adquirindo ao longo da vida, então, a coisa é um processo, não é uma situação só, é um processo de coisas que vem acontecendo, ao mesmo tempo em que eles acham frescura [...] eu sinto que tem uma pontinha de inveja, não inveja, mas assim, vê que você "tá" bem, você "tá" com uma cara boa, tua saúde é boa, eu não fico doente graças a Deus, é muito difícil eu ficar doente, tenho disposição para fazer as coisas. (P9 - Professor de Musculação e personal trainer, 52 anos)

A terceira idade para mim nada mais é que a resposta do que você foi a vida inteira. Se você foi um cara que se dedicou a ter bons hábitos sua terceira idade vai ser boa, se não foi, você pode ter certeza que você vai pagar caro com isso [...] você não pode ser "largadão" não, senão você vai pagar caro, cheque alto no final. (P21 - Personal trainer, 45 anos)

Debert (2004) afirma que a velhice para os sujeitos acaba se tornando, equivocadamente, uma questão de escolha individual, resultado de descuidos pessoais em não se envolver em atividades motivadoras ou incapazes de adotar certas condutas para combater o envelhecimento. O cuidado de si ao longo dos anos pode ser desgastante na medida em que as preocupações com/para o corpo e a saúde são constantes para esse profissional. Se para a população em geral ao envelhecer, a preocupação cultural de estar "ativa" fisicamente é expressiva (KATZ, 2000; TULLE, 2008), o professor de Educação Física pode ser obrigado a lutar contra o envelhecimento, preocupando-se com seu corpo igualmente (ou até mais?) do que outros sujeitos. 
O corpo é a referência da área de Educação Física, acarretando possivelmente em seus profissionais uma vigilância do corpo como uma responsabilidade diante da velhice (BAGRICHEVSKY, 2009). Conforme os próprios professores, a saúde ou o "estado" de saúde é provindo eminentemente de comportamentos de risco ${ }^{2}$ assumidos e regulados pela pessoa durante toda vida. Muitas vezes o sujeito se sente culpado e com certa responsabilidade pela sua própria saúde (PALMA et al., 2003; ORTEGA, 2003).

\section{ConClusões}

Tendo em vista que o objetivo desta pesquisa foi investigar se (e quais são os significados atribuídos) a saúde emerge nas relações entre o envelhecimento do professor de Educação Física e seu próprio corpo, foram verificadas certas tendências, provavelmente, particulares e/ou inéditas na área.

Pensando no próprio envelhecer, as preocupações consideradas mais importantes pelos professores de Educação Física foram diversificadas. A necessidade de ter ou manter a funcionalidade do corpo relativa à saúde, além de estar relacionada à demanda de cumprir determinados papéis sociais e culturais, sugere um receio típico do professor da área de Educação Física na medida em que a natureza do cotidiano profissional exige uma capacidade físicobiológica, que pode se comprometer ao longo dos anos. A busca da estabilidade financeira associada à saúde demonstra que o envelhecer na profissão pode limitar as condições do modo de viver e de conseguir trabalhar no futuro. Em relação ao receio de doenças, o professor associa, normalmente, a "falta de saúde" ao corpo envelhecido - leia-se velho. Por fim, destaca-se que a dimensão mental surge timidamente, demonstrando uma concepção dualista de corpo, uma vez as preocupações com o envelhecimento estavam centradas eminentemente na dimensão física.

${ }^{2}$ Os comportamentos de risco, de acordo com Palma et al. (2003), se referem aos hábitos, atitudes e/ou situações que podem se associar à presença de doenças. 
Já os cuidados que os professores de Educação Física mais adotam para um envelhecer saudável são as práticas corporais e a adoção de uma alimentação equilibrada, transparecendo que, para a maioria dos investigados, há certo automonitoramento da exposição aos comportamentos de risco ao longo da vida. Desse modo, percebese que o próprio profissional, que cuida ou lida com as preocupações corporais dos alunos, encarna basicamente a responsabilidade de se manter saudável a partir de investimentos individuais no/para o corpo com o intuito de retardar ou monitorar o passar dos anos, como se fosse isento de inúmeros fatores socioculturais.

Os significados atribuídos ao corpo e à saúde pelo profissional investigado devem ser vistos à luz do processo de envelhecimento do professor de Educação Física em determinadas condições e contex to histórico-social, o que confere singularidade aos achados aqui descritos. Desta maneira, outras interpretações poderiam emergir se fossem considerados outros aspectos.

Recomenda-se mais estudos que busquem identificar tais significados atribuídos ao corpo, à saúde e ao envelhecimento pelo/ do professor de Educação Física, levando em consideração, por exemplo, cada âmbito de atuação de trabalho, as fases da carreira docente, bem como as possíveis diferenças entre gêneros e condições socioeconômicas, aspectos esses ainda pouco explorados e que enriqueceriam sobremaneira as abordagens sobre o assunto. 


\begin{abstract}
Eventual relations among body, health and the ageing of the Physical Education teacher

Abstract: In the literature review it was noticed that there is no studies related to how the process of ageing can affect the physical education teacher. This study aims to investigate if the health emerges (and what are the meanings) in the relations between the process of ageing of the physical education teacher and his own body. The main worries about ageing are related to the functionality of the body, financial stability, being old and not to have diseases. Concerning to ageing in a healthy way, the teacher's cares are related to physical activities and the adoption of an equilibrated alimentation.
\end{abstract}

Keywords: Body. Aging. Faculty. Physical Education.

Posibles relaciones entre el cuerpo, salud y el envejecimiento del profesor de Educación Física Resumen: Se nota en la literatura la escasez de estudios sobre como el envejecer puede afectar al profesor de Educación Física. El objetivo del presente estudio fue investigar si (y cuáles son los significados atribuidos) la salud emerge en las relaciones entre el envejecimiento del profesor de Educación Física y su propio cuerpo. La funcionalidad del cuerpo, la estabilidad financiera, no tener enfermedades y volverse senil, aspectos esos imbricados con la salud, son las preocupaciones del profesor al envejecer. Los cuidados que el profesor adopta para un envejecer saludable son las prácticas corporales y la adopción de una alimentación equilibrada.

Palabras clave: Cuerpo. Envejecimiento. Docentes. Educación Física.

\section{REFERÊNCIAS}

BAGRICHEVSKY, M.; PALMA, A. Questionamentos e incertezas acerca do estatuto científico da saúde: um debate necessário na Educação Física. Revista da Educação Física/UEM, Maringá, v. 15, n. 2, p. 57-66, 2. sem. 2004.

BAGRICHEVSKY, M. Del "cuerpo saludable" que se (des)constituye. Revista Brasileira de Ciências do Esporte, Campinas, v. 30, n. 3, p. 191-202, maio 2009. 
BARROS, M. M. L. Testemunho de vida: um estudo antropológico de mulheres na velhice. In: BARROS, M. M. L. (Org.) Velhice ou terceira idade? Estudos antropológicos sobre identidade, memória e política. 4. ed. Rio de Janeiro: Ed. FGV, 2007. p. $113-168$

BLESSMANN, E. J. Corporeidade e envelhecimento: o significado do corpo na velhice. Estudos Interdisciplinares sobre o envelhecimento, Porto Alegre, v. 6, p. 21-39, 2004.

DEBERT, G. G. A reinvenção da velhice: socialização e processos de reprivatização do envelhecimento. São Paulo: EDUSP; FAPESP, 2004.

GARDNER, P. J. Envelhecimento saudável: uma revisão das pesquisas em língua inglesa. Movimento, Porto Alegre, v. 12, n. 2, p. 69-92, mai./ago. 2006.

GASKELL, G. Entrevistas individuais e grupais. In: BAUER, M. W.; GASKEL, G. (Ed.). Pesquisa qualitativa com texto, imagem e som: um manual prático. 2.ed. Trad. Pedrinho A. Guareschi. Petrópolis/RJ: Vozes, 2003. p. 64-89.

HUBERMAN, M. O ciclo de vida profissional dos professores. In: NÓVOA, A. (Org.) Vida de professores. 2. ed. Porto: Porto Editora, 2007. p. 31-61.

KATZ, S. Busy bodies: activity, aging, and the management of everyday life. Journal of Aging Studies, Colombia,MISS, v. 14, n. 2, p. 135-152, 2000.

LAZ, C. Age embodied. Journal of Aging Studies, Colombia, MISS, v. 17, p. 503519, 2003.

LE BRETON, D. Adeus ao corpo: antropologia e sociedade. Campinas, SP: Papirus, 2003.

LÜDORF, S. M. A. Formação de professores de Educação Física: retratos de uma instituição. Revista Brasileira de Docência, Ensino e Pesquisa em Educação Física, Cristalina, v. 2, n. 1, p. 126-136, jul. 2010.

LUPTON, D. Corpos, prazeres e práticas do eu. Educação e Realidade, Porto Alegre, v. 25, n. 2, p. 15-48, jul./dez. 2000.

MINAYO, M. C. Contribuições da antropologia para pensar e fazer saúde. In: CAMPOS, G. W. S. et al. (Orgs.) Tratado de saúde coletiva. São Paulo: Hucitec; Rio de Janeiro: Ed. Fiocruz, 2006. p. 189-218.

NÓVOA, A. Os professores e as histórias da sua vida. In: NÓVOA, A. (Org.) Vida de professores. 2. ed. Porto: Porto Editora, 2007. p. 11-30.

ORTEGA, F. Práticas de ascese corporal e constituição de bioidentidades. Cadernos Saúde Coletiva, Rio de Janeiro, v. 11, n. 1, p. 59-77, 2003.

PALMA, A. et al. Reflexões acerca da adesão aos exercícios físicos: comportamentos de risco ou vulnerabilidade? Movimento, Porto Alegre, v. 10, n. 21, p. 83-100, set./dez. 2003. 
PETRY, L.; GARCES, S. B. B. A percepção do processo de envelhecimento no contexto de trabalho dos professores de Educação Física. Lecturas en Educación Física y Deportes, Buenos Aires, v. 14, n. 132, mayo 2009. Disponível em: (http://www.efdeportes.com/efd132/a-percepcao-do-processo-deenvelhecimento.htm). Acesso em: 14 set. 2010.

SILVA, J. V. P.; NUNEZ, P. R. M. Qualidade de vida, perfil demográfico e profissional de professores de Educação Física. Pensar a Prática, Goiânia, v. 12, n. 2, p. 1-11, mai./ago. 2009.

STANO, R. C. M. T. Identidade do professor no envelhecimento. São Paulo: Cortez, 2001.

TARDIF, M.; RAYMOND, D. Saberes, tempo e aprendizagem do trabalho no magistério. Educação e Sociedade, Campinas, v. 21, n. 73, p. 209-244, dez. 2000.

TULLE, E. Acting your age? Sports science and the ageing body. Journal of Aging Studies, Colombia, MISS., v. 22, p. 340-347, 2008.

TURATO, E. R. Tratado da metodologia da pesquisa clínico-qualitativa: construção teórico-epistemológica, discussão comparada e aplicação nas áreas da saúde e humanas. 2. ed. Petrópolis: Vozes, 2003.

VICTORA, C.; KNAUTH, D.; HASSEN, M. N. A. A pesquisa qualitativa em saúde: uma introdução ao tema. Porto Alegre: Tomo Editorial, 2000.

VINCENT, J. A. The cultural construction old age as a biological phenomenon: science and anti-ageing technologies. Journal of Aging Studies, Colombia,MISS., v. 22 , p. 331-339, 2008.

Auxílio FAPERJ

Endereço para correspondência:

Alan Camargo Silva

Av. Marechal Henrique Lott, 70 / apt. 1014 - Barra da Tijuca

Rio de Janeiro/RJ. CEP: 22631-370

Recebido em: 01.03.2011

Aprovado em: 23.05.2012 
